\title{
Operário, tome a máquina! Tome a terra, camponês!
}

\author{
Élisée Reclus \\ Tradução: \\ Sergio Aparecido Nabarro \\ Université Paris I, Panthéon Sorbonne \\ Paris, França \\ e-mail: sergionabarro@gmail.com \\ (D) 0000-0003-2179-0710
}

p. $407-409$

\section{revista}

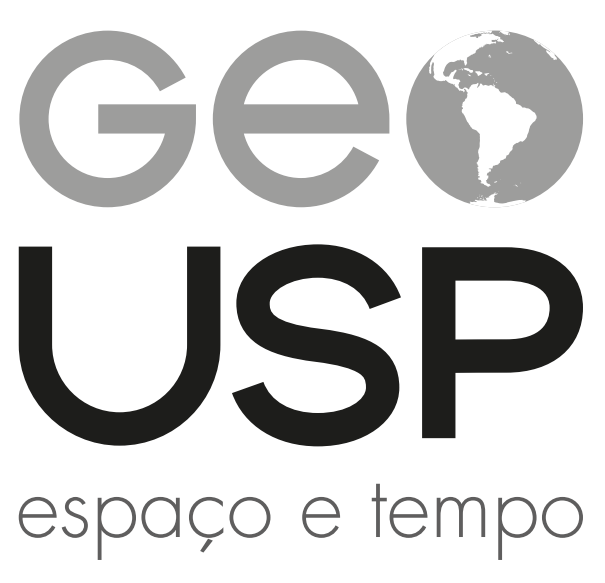

Volume $24 \cdot n^{\circ} 2$ (2020)

ISSN 2179-0892
Como citar este artigo:

RECLUS, E. Operário, tome a máquina! Tome a terra, camponês! Trad. Sergio Aparecido Nabarro. Geousp Espaçoe Tempo(On-line), v. 24, n. 2, p. 407-409, ago. 2020. ISSN 2179-0892.

Disponível em: https://www.revistas.usp.br/geousp/article/ view/166512. doi: https://doi.org/10.11606/issn.2179-0892. geousp.2020.166512.

\section{(c) $\underset{\mathrm{BY}}{\mathrm{BY}}$}

Este artigo está licenciado sob a Creative Commons Attribution 4.0 Licence 


\title{
Operário, tome a máquina! Tome a terra, camponês! ${ }^{1}$
}

\author{
Élisée Reclus \\ Tradução: Sergio Aparecido Nabarro
}

Nossos inimigos, os defensores da propriedade privada, sempre alegaram que seu melhor aliado é o camponês dono de suas terras. Por ouvi-los, Jacques Bonhomme vigia dia e noite seu lote, esperando algum trabalhador "socialista terrível" para agarrá-lo ou pendurá-lo num canto de seu celeiro. De acordo com eles, a diferença de interesses entre o camponês e o trabalhador urbano é tal que o antagonismo das duas classes deve permanecer para sempre e, naturalmente, eles contam com esse ódio mortal para manter seu poder e seu dinheiro.

Mas o que há de verdade nisso?

Sem dúvida, é grande a diferença entre o camponês, dono de um pedaço de terra, e o trabalhador urbano, que tem apenas seu corpo enfraquecido pela fome. Portanto, não é justo comparar um com o outro. A comparação deve ser feita entre os verdadeiros proletários, tanto do campo quanto das cidades, entre aqueles que, de ambos os lados, dependem, para a realização do trabalho, da boa vontade de um senhor. E os senhores economistas ignoram que, mesmo na França, país caracterizado pela pequena propriedade, os pobres da terra somam milhões? Eles não sabem que em quase todos os países da Europa o camponês está, assim como o operário da indústria, destinado à miséria irremediável? Não admitem que, na Inglaterra, pátria dessa tão apregoada economia política, o lavrador seja um vil mercenário, "tão reles", diz a Revista Fortnightly, "que se ele recebesse um pedaço de terra, não saberia o que fazer com ela?" É um retrato encantador da vida campestre, tal como declamam os poetas e pintam os artistas. Árvores frondosas, rios de água pura, um celeiro transbordando de feixes, animais de pelos brilhantes brincando no quintal, uma camponesa com seu bebê, rodeada de crianças brincando, recebendo sorridente o homem que volta dos campos, uma lareira, a comida quente na mesa vista pela porta entreaberta; tudo tão gracioso e doce. Mas agora vá à Silésia e veja em que drama horrível esse romance se transformou. Lá, não há mais fogo, nem refeições, nem roupas: homens, mulheres e crianças estão doentes ou moribundos sobre seus leitos de palha ou na terra nua, e ratos famintos vêm devorar os cadáveres! É isso que o regime da propriedade privada quer! A terra pertence a alguns grandes personagens: o que é uma pena para aqueles que não nasceram príncipes ou que sua estrela da sorte não os fez banqueiros!

Ora, a história contemporânea nos prova que esse regime de propriedade capitalista está se desenvolvendo cada vez mais e, fatalmente, pelo desenvolvimento normal das leis econômicas,

Texto escrito pelo anarquista e geógrafo francês Jacques Élisée Reclus em 1880, durante seu segundo período no exílio (dessa vez, em Genebra), e publicado no mesmo ano pela Fédération Jurassienne, seção anarquista criada e dirigida por James Guillaume. Trata-se de um texto cujo objetivo era convocar os trabalhadores para a luta contra a precarização do trabalho e da vida imposta pela dinâmica do capitalismo do século XIX.

Traduzido por Sergio Aparecido Nabarro a partir do panfleto original:

RECLUS, Élisée. Ouvrier, prends la machine! Prends la terre, paysan! Genève: Imprimerie Jurassienne, 1880. 
a pequena propriedade deve ser devorada pela grande; a terra camponesa será incorporada às grandes propriedades, assim como as pequenas oficinas serão incorporadas pelos proprietários das fábricas, e os grandes banqueiros enriquecerão com a ruína dos pequenos especuladores. A esse respeito, nada é mais instrutivo que a correspondência publicada nos grandes jornais ingleses sobre a exploração da terra, como a praticada atualmente nos estados mais férteis da república norte-americana.

Que os camponeses da Europa se mantenham informados! Não duvidem se, em breve, os capitalistas fizerem aqui o que eles consideraram adequado fazer a oeste do Atlântico; sem dúvida, aprenderão a fazê-lo na margem oposta! Precisamente aqueles que nos dão informações sobre as explorações americanas são comissários encarregados pelo governo inglês da tarefa de importar bons métodos agrícolas para a Europa.

Como exemplo dessas fazendas americanas, tomemos a de Casselton, localizada nas planícies que se estendem a oeste do lago Superior: uma companhia ferroviária, que mantém boas relações com o governo, como todas as grandes corporações financeiras, recebeu nessa região uma área de 30.000 hectares para explorar: isso é um pouco mais do que a superfície do cantão de Genebra. Essa grande área foi confiada a um hábil fazendeiro, que tinha feito fortuna em outro lugar, e esse homem se estabeleceu no meio do nada para transformar a área numa usina de trigo, tabaco e feno. Em seus galpões, ele possui 100 arados, 100 semeadoras, 100 colhedeiras e 20 debulhadoras; tem ainda cerca de 50 vagões ferroviários, que entram e saem incessantemente do campo para o porto mais próximo, cujo cais e os navios também pertencem à companhia. Uma rede de telefones liga a casa central a todas as construções da propriedade; a voz desse senhor é ouvida em todos os lugares, ele ouve todos os ruídos, nada é feito sem suas ordens ou longe de sua supervisão.

Quanto às ferramentas vivas dessa usina, são 400 cavalos e 600 homens. Os estábulos estão dispostos de tal modo que, na saída, os animais começam a traçar um percurso que se estende por vários quilômetros até o limite da propriedade: cada um de seus passos é usado pelo proprietário eficiente. E percebemos que isso também acontece com o uso da força humana. Todos os movimentos dos trabalhadores são rigorosamente controlados desde a sua saída do alojamento. Não há crianças nem mulheres para atrapalhar o serviço. Os trabalhadores são agrupados por esquadrões, com seus capitães e sargentos. Seu único dever é obedecer e manter-se em silêncio nas fileiras. No fim do outono, todo o exército é demitido, restando apenas dez homens para vigiar os estábulos. No ano seguinte, os recrutadores chamam outros soldados, porque a empresa não emprega os mesmos trabalhadores: isso poderia fazê-los pensar que um torrão de terra poderia lhes pertencer!

É esse o modelo ideal de exploração agrícola que os agrônomos dos Estados Unidos e da Inglaterra classificam como exemplar? De fato, os resultados financeiros são admiráveis. Com 400 cavalos e 600 homens empregados por sete meses, obtém-se uma quantidade de trigo que representa o alimento de, pelo menos, 50 mil pessoas. Um exemplo triunfante do que pode ser obtido pela grande cultura científica, mas não menos impressionante exemplo do monopólio que alguns capitalistas podem reivindicar sobre o trabalho e a vida de todos! 
E que destino terrível esses avanços industriais estão preparando para todos os trabalhadores, operários e camponeses, se o direito de concentrar a terra for mantido, se grandes áreas foram mantidas nas mãos de poucos! É ótimo que um homem operando máquinas possa fornecer produtos suficientes para centenas de pessoas; mas, nesse caso, qual a necessidade da existência do proprietário para a multidão de trabalhadores que vão até ele? Por toda parte, o trabalho está se tornando mais simples, e o número de trabalhadores aumenta. Onde trabalhavam dez homens, agora basta um; onde se produziam dez, agora se produzem 100. Em todos os lugares, os desempregados cercam as oficinas, e o capitalista pode, ano após ano, pagar salários mais baixos e manter como empregados apenas os trabalhadores mais dóceis e sóbrios. Se o francês for demasiado motivado, se for demasiado independente, será substituído pelo alemão! Se o alemão comer demais, ele será substituído pelo chinês! $\bigcirc$ mesmo acontece com a economia política! É a lei da oferta a da procura, é a lei do mais forte! E não haverá nenhuma diferença entre a fábrica das cidades e a usina dos campos. $\bigcirc$ camponês dono de um pedaço de terra pode aproveitar sua existência, assim como o artesão e o pequeno-burguês, pois chegará o momento em que toda a concorrência com o grande explorador da terra, servido pelo capital e pela máquina, se tornará completamente impossível; nesse dia, tudo o que lhe restará será tornar-se mendigo.

A menos que, finalmente, unido ao operário, seu companheiro na labuta e na miséria, ele tenha recuperado a propriedade coletiva!

\section{Operário, tome a máquina! Tome a terra, camponês!}

